\title{
The Danish Ventral Hernia Database - a valuable tool for quality assessment and research
}

This article was published in the following Dove Press journal:

Clinical Epidemiology

25 October 2016

Number of times this article has been viewed

\section{Frederik Helgstrand' Lars Nannestad Jorgensen ${ }^{2}$ \\ 'Department of Surgery, Køge Hospital, University of Copenhagen, Køge, Denmark; ${ }^{2}$ Digestive Disease Center, Bispebjerg Hospital, University of Copenhagen, Copenhagen NV, Denmark}

Aim: The Danish Ventral Hernia Database (DVHD) provides national surveillance of current surgical practice and clinical postoperative outcomes. The intention is to reduce postoperative morbidity and hernia recurrence, evaluate new treatment strategies, and facilitate nationwide implementation of evidence-based treatment strategies. This paper describes the design and purpose of DVHD.

Study population: Adult ( $\geq 18$ years) patients with a Danish Civil Registration Number and undergoing surgery under elective or emergency conditions for ventral hernia in a Danish surgical department from 2007 and beyond. A total of $80 \%$ of all ventral hernia repairs performed in Denmark were reported to the DVHD.

Main variables: Demographic data (age, sex, and center), detailed hernia description (eg, type, size, surgical priority), and technical aspects (open/laparoscopic and mesh related factors) related to the surgical repair are recorded. Data registration is mandatory. Data may be merged with other Danish health registries and information from patient questionnaires or clinical examinations.

Descriptive data: More than 37,000 operations have been registered. Data have demonstrated high agreement with patient files. The data allow technical proposals for surgical improvement with special emphasis on reduced incidences of postoperative complications, hernia recurrence, and chronic pain.

Conclusion: DVHD is a prospective and mandatory registration system for Danish surgeons. It has collected a high number of operations and is an excellent tool for observing changes over time, including adjustment of several confounders. This national database registry has impacted on clinical practice in Denmark and led to a high number of scientific publications in recent years.

Keywords: database management system, registries, ventral hernia, outcome, national, morbidity

\section{The Danish Ventral Hernia Database}

The Danish Hernia Database is subdivided into an inguinal hernia database and a ventral hernia database. This article refers to the Danish Ventral Hernia Database (DVHD) that includes repairs of all abdominal wall hernias excluding inguinal and femoral hernias. Thus, the database includes all primary (umbilical, epigastric, and others) as well as secondary hernias (incisional and parastomal).

Digestive Disease Center K, Bispebjerg

Hospital, DK-2400 Copenhagen NV,

Denmark

Tel +45 20727709

Fax +45 3531 391।

Email larsnjorgensen@hotmail.com

\section{Aim}

With reference to ventral hernia repair, the database is designed to provide national surveillance of current Danish surgical practice and clinical postoperative outcomes. 
This database facilitates mapping of the incidence of surgery, aspects of surgical techniques, and postoperative complications.

It is specifically intended that the data generated by the database must contribute to reduction of postoperative morbidity and hernia recurrence. Moreover, it seeks to evaluate new treatment strategies and facilitate nationwide implementation of evidence-based treatment strategies.

\section{Study population}

The database includes all adult ( $\geq 18$ years) Danish patients operated on under elective or emergency conditions for ventral hernia in a Danish surgical department (public, $n=22$ or private, $n=10$ ). The database includes both primary hernia repairs and repairs for recurrences. All centers contributed with registration of hernia procedures since the launch of the database in 2007. The annual number of operations recorded in the database varies between 4,300 and 4,800. A total of more than 37,000 operations have now been registered.

\section{Main variables}

Data entry is most often performed by the operating surgeon immediately after surgery on a secured website using the patient's unique Danish Civil Registration Number. The variables that are recorded include demographic data, detailed hernia description, and technical aspects related to the surgical repair (Table 1). Data entry is kept simple and uniform, and it is possible to monitor different variables depending on the type of hernia repair. In order to eliminate missing data, the system does not accept upload of insufficient registrations. Data registration is mandatory and has been validated against patient files (gold standard) demonstrating more than $94 \%$ overall agreement on parameters, such as type of hernia, hernia size, mesh product, and mesh fixation. ${ }^{1}$

\section{Follow-up}

A continuous follow-up is performed by a preprogrammed and automatic merge of data from DVHD with data from the Danish National Patient Register (DNPR), ${ }^{2}$ which holds data from all patient contacts, to the Danish health care providers (private and public), including operations. This merging of data relies on the unique Danish Civil Registration Number of the patient. This combination of data is performed on a monthly basis to provide quality assessment given by four defined clinical indicators (Table 2). Additionally, other registered outcome measures can be obtained from DNPR

Table I Variables in the Danish Ventral Hernia Database

\begin{tabular}{|c|c|c|c|}
\hline Type & Variable & Drop-down menu one & Drop-down menu two \\
\hline \multirow[t]{7}{*}{ Demography } & Surgical department & & \\
\hline & Surgeon's initials & & \\
\hline & Sex & & \\
\hline & Age & & \\
\hline & Date of repair & & \\
\hline & Comorbidity & Organ dysfunction requiring & \\
\hline & & medical treatment & \\
\hline \multirow[t]{11}{*}{ Hernia specifications } & Surgical setting & Elective or emergent & \\
\hline & Primary or recurrent & Number of recurrence & \\
\hline & Type of hernia & Incisional & Orientation of primary incision \\
\hline & & Umbilical & \\
\hline & & Epigastric & \\
\hline & & Parastomal & \\
\hline & & Trocar-site & \\
\hline & & Other & Specification \\
\hline & Number of hernia defects & & \\
\hline & Size of hernia & Maximum transverse and & \\
\hline & & longitudinal diameter & \\
\hline \multirow[t]{10}{*}{ Procedure specifications } & Open, laparoscopic, or & & \\
\hline & laparoscopic converted to open & & \\
\hline & Component separation & Uni/bilateral & \\
\hline & & Endoscopic or open & \\
\hline & Sutured repair of defect & Type of suture & \\
\hline & Mesh repair & Product name and type & \\
\hline & & Mesh position & Onlay, sublay, inlay, \\
\hline & & & intraperitoneal, other \\
\hline & & Mesh fixation & Sutures, tackers, other \\
\hline & Antibiotic prophylaxis & & \\
\hline
\end{tabular}


Table 2 Quality indicators in the Danish Ventral Hernia Database following ventral hernia repair

\begin{tabular}{|c|c|c|c|}
\hline Indicator & Specification & Results, year 2014 & $\begin{array}{l}\text { Recommended } \\
\text { standard }\end{array}$ \\
\hline $\begin{array}{l}\text { Duration of hospital } \\
\text { stay }\end{array}$ & $\begin{array}{l}\text { Duration of admission after } \\
\text { initial hernia repair }\end{array}$ & $\begin{array}{l}\text { Median } 0 \text { days (inter-quartile } \\
\text { range: } 0-\mid \text { days) }\end{array}$ & $<4$ days \\
\hline Readmission & 30-day readmission rate & $\begin{array}{l}9 \%(95 \% \text { confidence interval: } \\
9 \%-10 \%)\end{array}$ & $<15 \%$ \\
\hline Early reoperation & $\begin{array}{l}\text { 30-day reoperation rate for } \\
\text { complication }\end{array}$ & $\begin{array}{l}3.1 \%(95 \% \text { confidence interval: } \\
2.6 \%-3.7 \%)\end{array}$ & $<5 \%$ \\
\hline Mortality & 30-day mortality rate & $\begin{array}{l}0.4 \text { ( } 95 \% \text { confidence interval: } \\
0.3 \%-0.7 \%)\end{array}$ & $<0.5 \%$ \\
\hline
\end{tabular}

following approval. Such measures may include reoperation for hernia recurrence, specific diagnoses, and other surgical procedures.

\section{Examples of research}

Since the establishment of DVHD in 2007, there has been an intensive scientific activity resulting in national collaboration and many international publications within the field (http://www.herniedatabasen.dk/index.php/downloads/ litteraturliste/).

\section{Technical aspects}

Based on the combination of the prospectively collected data from the DVHD and follow-up in the DNPR, high volume data have been analyzed and have provided evidence for surgical improvement. ${ }^{3,4}$ High complication rates have been documented for all types of elective ventral hernia repairs s $^{3,5-8}$ and after emergency repairs, which are associated with up to 15 -fold increase of morbidity. ${ }^{8,9}$ The nationwide studies have pointed out several areas for surgical improvement for the different types of ventral hernias to reduce risk for early and late complications and recurrence. These include the advantageous application of a sublay mesh during open repair of an incisional hernia ${ }^{7}$ and use of a mesh for open umbilical or epigastric hernia repair to reduce recurrence. ${ }^{10}$

\section{Pain}

Combining data from the DVHD with data from patient files, patient questionnaires, and clinical examinations revealed that mesh repairs reduce the risk for recurrence significantly, ${ }^{7}$ even in small repairs and without increased risk of pain. ${ }^{10,11}$ Additionally, large-size data from DVHD have shown that laparoscopic intraperitoneal mesh fixation with absorbable as compared with titanium tacks is associated with an increased risk of hernia recurrence. Contrary to previous expectations by manufacturers of mesh fixation devices, there was no difference in long-term pain between patients receiving absorbable tacks and patients operated on with titanium tacks. ${ }^{12}$

\section{Clinical hernia recurrence versus reoperation for recurrence}

Data from DVHD have been combined with information obtained from DNPR and clinical examinations to determine the cumulated incidence difference between a recurrent hernia diagnosed by clinical examination and reoperation for hernia recurrence. Clinical recurrences were four- to fivefold higher than the number of reoperations for recurrence. ${ }^{13}$ Earlier reports based on reoperation rates for hernia recurrence thus severely underestimate the real frequency of hernia recurrence.

\section{Herniogenesis}

The link between specific databases according to a unique Danish Civil Registration Number for each patient allows for combining scientifically interesting data from various databases. Findings were recently published combining data from DVHD with information from the Danish Inguinal Hernia Database. Interestingly, patients operated on for a direct or recurrent inguinal hernia as compared with surgery for an indirect inguinal hernia were significantly more prone to ventral hernia repair suggesting a specific predisposition to herniogenesis. ${ }^{14}$

It has been suggested in small studies that abdominal aortic aneurism shares common pathological mechanisms with the development of incisional hernia. Merging data from DVHD, the Danish Vascular Surgery Registry and DNPR allowed for the largest study ever in this field. It demonstrated that both obesity and aortic reconstruction due to abdominal aortic aneurism as compared with aortoiliac occlusive disease significantly increased the risk of subsequent incisional hernia repair. ${ }^{15}$ However, contrary to findings of previous low-powered studies, the presence of abdominal aortic aneurism in a large screening population was not associated with diagnosis of inguinal hernia. ${ }^{16}$ 


\section{National initiatives}

The prospective Danish hernia databases were among the first in the field and the only ones requiring mandatory registration by all surgeons conducting hernia repairs. It is crucial for the quality of the databases that a high registration rate is maintained. This is facilitated by a number of ongoing initiatives, including meetings for surgeons providing feedback information twice annually. Moreover, lists of unregistered procedures are generated on a monthly basis and distributed to the surgical centers. Finally, a national report is published every year on main statistics and center-based reporting rates to the registries. The national rate of registration to the DVHD is $\sim 80 \%$ as compared to the rate for the Danish Inguinal Hernia Database that reaches $\sim 90 \%$. There is an ongoing initiative from the Steering Committee of DVHD to motivate all surgeons to report their operations in order to increase the national registration rate. Moreover, there is political focus on annual reports which are sent to the administrators and chairman of each surgical center informing on the local registration rate. However, there are no judicial options to increase the registration rate.

The data collected from the hernia databases combined with information from DNPR and other specific databases provide scientific evidence for revised recommendations and guidelines following discussion between participating surgeons at regular meetings. The guidelines are published on the website of the hernia database (http://www.herniedatabasen. $\mathrm{dk} /$ ).

\section{Administrative issues and funding}

Since establishment in 2007, the DVHD has been funded by the Danish government. The funds also cover the Inguinal Hernia Database. All operational aspects of the database are handled by the steering committee. The annual budget, including statistical and logistical support, is $\sim € 40,000$. Approximately half of the funding covers fees, travel, and meeting expenses. The majority of core structural tasks within the database is controlled and maintained by government organizations (Regionernes Kliniske Kvalitetsudviklings Program). Data analyses, quality reports, and scientific contributions are based on voluntary work.

Data access: Each participating center may obtain their data. In order to obtain data from external centers, approval is required from the Danish Data Protection Agency and Regionernes Kliniske Kvalitetsudviklings Program.

\section{Conclusion}

The DVHD is a prospective and mandatory national registration system for Danish surgeons. It has collected a high number of operations within a short period of time. The high rate of registration provides data reflecting current clinical practice. Each participating surgeon has the opportunity of obtaining data from his/her center. The registration requires a limited contribution from all surgeons and is an excellent tool for observing changes over time, including adjustment of several confounders. The registration system permits post hoc subgrouping of patients at high risk and may investigate even rare clinical events. Finally, this national database registry has led to a high number of scientific publications in recent years.

\section{Acknowledgments}

We thank members of the Steering Committee of the Danish Hernia Database for their creative process and contribution allowing for the logistics of the database. This paper was funded by the Program for Clinical Research Infrastructure (PROCRIN) established by the Lundbeck Foundation and the Novo Nordisk Foundation and administered by the Danish Regions. This review was conducted on behalf of the Danish Hernia Database.

\section{Disclosure}

Frederik Helgstrand was involved in educational activities for Bard-Davol and Ethicon, Johnson and Johnson. Lars Nannestad Jorgensen was involved in educational activities for Bard-Davol, Covidien, and Ethicon, Johnson and Johnson. The authors report no other conflicts of interest in this work.

\section{References}

1. Helgstrand F, Tenma J, Rosenberg J, Kehlet H, Bisgaard T. High agreement between the Danish Ventral Hernia Database and hospital files. Dan Med J. 2013;60(10):A4708.

2. Andersen TF, Madsen M, Jørgensen J, Mellemkjoer L, Olsen JH. The Danish National Hospital Register. A valuable source of data for modern health sciences. Dan Med Bull. 1999;46(3):263-268.

3. Helgstrand F, Rosenberg J, Bay-Nielsen M, et al. Establishment and initial experiences from the Danish Ventral Hernia Database. Hernia. 2010;14(2):131-135.

4. Helgstrand F, Rosenberg J, Jørgensen LN, Kehlet H, Bisgaard T. [Surgical treatment of ventral hernia]. Ugeskr Laeger. 2010;172(26): 1987-1989.

5. Helgstrand F, Jørgensen LN, Rosenberg J, Kehlet H, Bisgaard T. Nationwide prospective study on readmission after umbilical or epigastric hernia repair. Hernia. 2013;17(4):487-492.

6. Helgstrand F, Rosenberg J, Kehlet H, Bisgaard T. Nationwide analysis of prolonged hospital stay and readmission after elective ventral hernia repair. Dan Med Bull. 2011;58(10):A4322.

7. Helgstrand F, Rosenberg J, Kehlet H, Jorgensen LN, Bisgaard T. Nationwide prospective study of outcomes after elective incisional hernia repair. J Am Coll Surg. 2013;216(2):217-228.

8. Helgstrand F, Rosenberg J, Kehlet H, Jorgensen LN, Wara P, Bisgaard T. Risk of morbidity, mortality, and recurrence after parastomal hernia repair: a nationwide study. Dis Colon Rectum. 2013;56(11):1265-1272. 
9. Helgstrand F, Rosenberg J, Kehlet H, Bisgaard T. Outcomes after emergency versus elective ventral hernia repair: a prospective nationwide study. World J Surg. 2013;37(10):2273-2279.

10. Christoffersen MW, Helgstrand F, Rosenberg J, Kehlet H, Bisgaard T. Lower reoperation rate for recurrence after mesh versus sutured elective repair in small umbilical and epigastric hernias. A nationwide register study. World J Surg. 2013;37(11):2548-2552.

11. Christoffersen MW, Helgstrand F, Rosenberg J, Kehlet H, Strandfelt P, Bisgaard T. Long-term recurrence and chronic pain after repair for small umbilical or epigastric hernias: a regional cohort study. Am J Surg. 2015;209(4):725-732.

12. Christoffersen MW, Brandt E, Helgstrand F, et al. Recurrence rate after absorbable tack fixation of mesh in laparoscopic incisional hernia repair Br J Surg. 2015;102(5):541-547.
13. Helgstrand F, Rosenberg J, Kehlet H, Strandfelt P, Bisgaard T. Reoperation versus clinical recurrence rate after ventral hernia repair. Ann Surg. 2012;256(6):955-958.

14. Henriksen NA, Sorensen LT, Bay-Nielsen M, Jorgensen LN. Direct and recurrent inguinal hernias are associated with ventral hernia repair: a database study. World J Surg. 2013;37(2):306-311.

15. Henriksen NA, Helgstrand F, Vogt KC, Jorgensen LN, Bisgaard T; Danish Hernia Database; Danish Vascular Registry. Risk factors for incisional hernia repair after aortic reconstructive surgery in a nationwide study. J Vasc Surg. 2013;57(6):1524-1530, 1530.e1-3.

16. Henriksen NA, Sorensen LT, Jorgensen LN, Lindholt JS. Lack of association between inguinal hernia and abdominal aortic aneurysm in a population-based male cohort. Br J Surg. 2013;100(11):1478-1482.
Clinical Epidemiology

\section{Publish your work in this journal}

Clinical Epidemiology is an international, peer-reviewed, open access, online journal focusing on disease and drug epidemiology, identification of risk factors and screening procedures to develop optimal preventative initiatives and programs. Specific topics include: diagnosis, prognosis, treatment, screening, prevention, risk factor modification,

Submit your manuscript here: http://www.dovepress.com/clinical-epidemiology-journal

\section{Dovepress}

systematic reviews, risk \& safety of medical interventions, epidemiology \& biostatistical methods, and evaluation of guidelines, translational medicine, health policies \& economic evaluations. The manuscript management system is completely online and includes a very quick and fair peer-review system, which is all easy to use. 